\section{In Vitro Segregation of Tetraploid and Octoploid Plantlets from Colchicine-induced Ploidy Chimeras in Echinacea purpurea $\mathrm{L}$.}

\author{
Qingling Li \\ Guangdong Key Laboratory for Innovative Development and Utilization of \\ Forest Plant Germplasm, South China Agricultural University, Guangzhou \\ 510642, China
}

\begin{abstract}
Yuesheng Yang ${ }^{1}$ and Hong Wu
Guangdong Key Laboratory for Innovative Development and Utilization of Forest Plant Germplasm, South China Agricultural University, Guangzhou 510642, China; and Guangdong Technology Research Center for Traditional Chinese Veterinary Medicine and Natural Medicine, South China Agricultural University, Guangzhou 510642, China
\end{abstract}

Additional index words. adventitious shoot formation, shoot tip multiplication, Grade-1 chimera, Grade-2 chimera, Grade-3 chimera

\begin{abstract}
Echinacea purpurea $\mathbf{L}$. is one of the important ornamental and medicinal plant species. Ploidy manipulation is a valuable tool for improving plant quality or production in E. purpurea as well as in many other plants. To study the segregation of pure ploidy plantlets from colchicine-induced ploidy chimeras in $E$. purpurea, we used a chimera plantlet that consisted of $1.93 \%$ diploid, $35.04 \%$ tetraploid, and $63.03 \%$ octoploid cells as the source material for experiments. The results showed that three factors significantly influenced the segregation, i.e., the component ratios of different ploidy cells in the chimera, the number of sequential passages, and the methods of segregation culture of the chimera plantlets. Other factors, such as explant types (i.e., leaf, petiole, or root) and 6-benzyladenine (BA) concentrations (i.e., $0.2,0.4,0.8$, and $1.2 \mathrm{mg} \cdot \mathrm{L}^{-1}$ ) occasionally influenced the segregation. Pure chromosome-doubled polyploids are not easily obtained in various plant species, so segregation culture of ploidy chimeras may potentially be more effective. The morphological characteristic and content of cichoric acid were compared among diploid, tetraploid, and octoploid plants. Results indicated that tetraploid and octoploid plants had more stunted growth, larger stomata, lower stomata frequency, more chloroplast number in guard cells, and higher cichoric acid content than original diploid lines.
\end{abstract}

Echinacea purpurea is an important herbaceous plant primarily native to North America (McGregor, 1968) and has received considerable attention for its ornamental and medicinal value in recent years. E. purpurea has long been a popular ornamental garden plant and was widely cultivated in the world. The key ornamental attribute of this species is the flower head that has beautiful colors, long flowering period, and could attract honeybees and butterflies. The whole flowering head (containing disk and ligules) diameter ranges from $3.5 \mathrm{~cm}$ to nearly $18 \mathrm{~cm}$ (Ault, 2007). A number of ornamental cultivars have been

\footnotetext{
Received for publication 19 Nov. 2015. Accepted for publication 21 Mar. 2016.

This research was funded by grants from a special program for Enterprise, University and Research Institute Cooperation of Guangdong Province and the Ministry of Education of China (2008B090500250) and Science and Technology Planning Project of Guangdong Province, China (2011B031700026).

${ }^{1}$ Corresponding author. E-mail: ysyang@scau.edu.cn.
}

developed in E. purpurea, such as 'Sparkler' (Harini, 2006a), 'Fancy Frills' (Harini, 2006b), 'Hope' (Harini, 2006c), 'Green Eyes' (Harini, 2006d), 'Raspberyy Tart' (Harini, 2008a), 'Mars' (Harini, 2008b), and so on. Except ornamental value, E. purpurea is one of the most well-known medicinal herbs in the world and has anti-inflammatory properties and immunoregulatory functions (Barrett, 2003). As its potential to replace antibiotics for treating human illness as well as livestock (Hudson, 2012; Landy et al., 2011; Pugh et al., 2008), the demand for E. purpurea products has increased vastly in recent years.

In breeding work, ploidy manipulation is a valuable tool for improving crop quality or production and polyploids promote evolution history significantly (Adams and Wendel, 2005; Leitch and Bennett, 1997; Otto and Whitton, 2000). Polyploidization often results in a wide range of changes on plants including morphology, physiology, cytology, and phytochemicals, and can also generate useful variants that provide innovative germplasm resources for breeding studies (Ramanna and Jacobsen, 2003; Thao et al., 2003). Polyploidy induction has been adopted as an efficient breeding strategy in many plant species, such as Astragalus membranaceus (Chen and Gao, 2007), Cymbopogon (Lavania et al., 2012), Dioscorea (Zhang et al., 2010), Humulus lupulus (Roy et al., 2001), Tanacetum parthenium (Majdi et al., 2010), and Zizyphus jujuba 'Zhanhua' (Gu et al., 2005). Colchicine has been successfully and widely used in polyploidy induction process ( $\mathrm{Gu}$ et al., 2005; Ning et al., 2009; Roy et al., 2001; Thao et al., 2003; Ye et al., 2010; Zhang et al., 2008). Colchicine is a compound that effectively arrests mitosis at the metaphase stage, so only the cells that are in metaphase stage could become polyploidized. However, the mitosis stages of the cells in meristematic tissues are not completely synchronous. Thus, we can find the areas where both original diploid and polyploidized cells are intermixed and are termed mixoploid or cytochimera (Dermen and Henry, 1944; Pryor and Frazier, 1968; Wan et al., 1989). This kind of chimera has frequently been observed in the process of chromosome doubling (Chen and Gao, 2007; Ning et al., 2009; Petersen et al., 2003; Roy et al., 2001; Thao et al., 2003).

In plant science, the term chimera refers to a plant that has at least two genetically different cell layers or groups as a result of mutation growing together in the apical meristem (Neilson-Jones, 1969; TilneyBassett, 1986). A chimera may develop in several ways: spontaneous mutation, chemical mutagenesis (such as colchicine treatment), grafting, or inheritance (Hartmann and Kester, 1990). Chimeras with different ploidy level cells are also called ploidy chimeras (i.e., mixoploid). Many previous studies used ploidy chimeras to trace the origination of each tissue (Dermen, 1953; Dermen and Stewart, 1973; Satina and Blakeslee, 1941; Satina et al., 1940) and investigate the fate of the apical or germ layers in the chimeras (Zonneveld, 2007). Chimeras can also be used to separate good variation for developing new cultivars in breeding work.

Polyploidization has also been confirmed to be highly effective in E. purpurea. In comparison with original diploid plants, $E$. purpurea tetraploid plants had a significantly higher biomass, higher contents of the main functional compounds, e.g., caffeic acid derivatives and alkamides, higher phenylalanine ammonia-lyase and cinnamate 4-hydroxylase activities, thicker roots that can facilitate harvesting and considerable larger stomatas, pollen grains, and seeds (Abdoli et al., 2013; Xu et al., 2013). Additionally, flower diameter of tetraploid plants was significantly larger than that in diploid plants (Abdoli et al., 2013). As we all know that flower is the key ornamental attribute of $E$. purpurea, so the ornamental value of tetraploid plants should be improved as compared with diploid lines.

During tetraploid induction in E. purpurea (Nilanthi et al., 2009a), chimeras were 
observed in almost all the treatments. This was similar to the reports in many other plant species, e.g., Alocasia (Thao et al., 2003), Dioscorea zingiberensis (Huang et al., 2010), Miscanthus sinensis (Petersen et al., 2003), Petunia hybrida (Ning et al., 2009), Punica granatum (Shao et al., 2003), and Rosa rugosa (Allum et al., 2007). In our study, we found more chimeras were produced than pure chromosome-doubled plants, and obtained a chimera plantlet simultaneously composed of diploid, tetraploid, and octoploid cells. This kind of chimera was observed for the first time in E. purpurea. Additionally, octoploid cells are only produced when diploid cell chromosomes double two times continuously, so we can infer that pure octoploid plantlets cannot be easily obtained in chromosome-doubling process. Furthermore, there are still no relative reports with respect to pure octoploid plantlets produced from chromosome doubling of diploid cells in E. purpurea. So this chimera plantlet is precious and segregating octoploid plantlets from it is important and compulsory. Using tissue culture method to separate chimeras into their consistent genotypes has been mostly accepted (Canli and Skirvin, 2003, 2008; Chen and Gao, 2007; Ning et al., 2009; Roy et al., 2001). The tissue culture system has been well established in $E$. purpurea (Choffe et al., 2000a, 2000b; Harbage, 2001; Koroch et al., 2002; Lakshmanan et al., 2002; Mechanda et al., 2003; Pan et al., 2004; Zobayed and Saxena, 2003). Adventitious shoot formation and shoot tip multiplication in vitro are the most common used methods for propagation in E. purpurea as well as in other plants (Manjula et al., 2015; Mazri, 2015; Nagar et al., 2015). Therefore, we used these two methods to segregate pure octoploid and tetraploid plantlets from the ploidy chimeras with the purpose of contributing to the segregation studies of other plant species.

Relative studies on segregation of ploidy chimeras were found in several plants (Huang et al., 2010; Ning et al., 2009; Roy et al., 2001; Shao et al., 2003). However, they just only separated chimeras into pure ploidy plants and did not describe the segregating process in detail. So the overall objectives of this research were: 1) to investigate the quantity changes of different ploidy level cells in the chimera plantlet; 2) to determine the effects of chimera type, explant type, sequential passage number, and BA concentration in segregation process; 3 ) to estimate the segregation efficiency of two methods; and 4) to compare the morphological characteristics and the important medicinal compound contents of diploid, tetraploid, and octoploid plants obtained in this study.

\section{Materials and Methods}

Plant source. The original diploid seeds were purchased from the Company of Plantation Products (Norton, MA) and were cultivated in the Garden of Chinese Medicinal Plants of South China Agricultural University.
The offspring seeds were collected and surface sterilized by immersion in $70 \%(\mathrm{v} / \mathrm{v})$ ethanol for $30 \mathrm{~s}$ and $1 \%$ sodium hypochlorite water solution for $10 \mathrm{~min}$. The sterile seeds were sown on Murashige and Skoog (MS) medium (Murashige and Skoog, 1962) and cultured for 2 months. Then the in vitro plantlets were prepared for the following colchicine treatment.

Colchicine treatment and ploidy level determination. The leaf, petiole, and root explants (leaf explants: $\approx 0.6 \mathrm{~cm}^{2}$, petiole and root explants: $\approx 0.8 \mathrm{~cm}$ in length) of in vitro diploid plantlets above were inoculated on MS medium containing $0.4 \mathrm{mg} \cdot \mathrm{L}^{-1} \mathrm{BA}$ and $0.01 \mathrm{mg} \cdot \mathrm{L}^{-1}$ naphthaleneacetic acid (NAA) for 3-d pretreatment and then transferred to the fresh medium of same composition supplemented with $100 \mathrm{mg} \cdot \mathrm{L}^{-1}$ colchicine for different treatment periods $(15,22,30,37$, and $47 \mathrm{~d})$. After colchicine treatment, all the treated explants were transferred to the same and fresh medium with pretreatment and cultured for $45 \mathrm{~d}$. Then the regenerated shoots from treated explants were cut and cultured on MS rooting medium containing $0.01 \mathrm{mg} \cdot \mathrm{L}^{-1} \mathrm{NAA}$ to become intact plantlets. The ploidy level determination was based on the observation of chromosome number. The detailed procedures are described in our previous research (Nilanthi et al., 2009a). At least three actively growing root tips were sampled for each plantlet. More than 50 metaphase cells that had clear chromosomes and could judge ploidy level were observed for each root tip. The plantlets were considered as diploids when all cells contained 22 chromosomes, as tetraploids when all cells contained 44 chromosomes, and as octoploids when all cells contained 88 chromosomes. The plantlets that contained two or more kinds of ploidy level cells were considered as chimeras.

Source chimera material and in vitro propagation. A chimera plantlet that simultaneously composed of diploid, tetraploid, and octoploid cells (Fig. 1A) arose in the treatment of petiole explant for 37-d colchicine duration. The ratios of diploid, tetraploid, and octoploid cells in this chimera plantlet were $1.93 \%$, $35.04 \%$, and $63.03 \%$, respectively. The ratios were calculated as follows. Five actively growing root tips were sampled, and more than 50 clear metaphase cells were observed for each root tip. After counting the number of different ploidy level cells, the proportion percentages of three different ploidy level cells in each root tip was obtained. Then, the weighted average of the proportion percentages from five root tips was as the final percentage data. The clear chromosome pictures of diploid, tetraploid, and octoploid cell were presented in Fig. 1B-D.

The leaf, petiole, and root explants (leaf explants: $\approx 0.6 \mathrm{~cm}^{2}$, petiole and root explants: $\approx 0.8 \mathrm{~cm}$ in length) were excised from the source chimera plantlet, and inoculated on MS medium containing $0.4 \mathrm{mg} \cdot \mathrm{L}^{-1} \mathrm{BA}$ and $0.01 \mathrm{mg} \cdot \mathrm{L}^{-1} \mathrm{NAA}$ for $45 \mathrm{~d}$. Then the regenerated shoots of all explants were cut and cultured on the same and fresh medium for shoot tip multiplication culture. After $45 \mathrm{~d}$, the multiplicated shoots were cut and transferred to rooting medium containing 0.1 $\mathrm{mg} \cdot \mathrm{L}^{-1}$ NAA to become intact plantlets. After $45 \mathrm{~d}$, all the intact plantlets were examined the ploidy states. At least three actively growing root tips for each plantlet were sampled and the proportion percentages of diploid, tetraploid, and octoploid cells for each plantlet were calculated using the method described above.
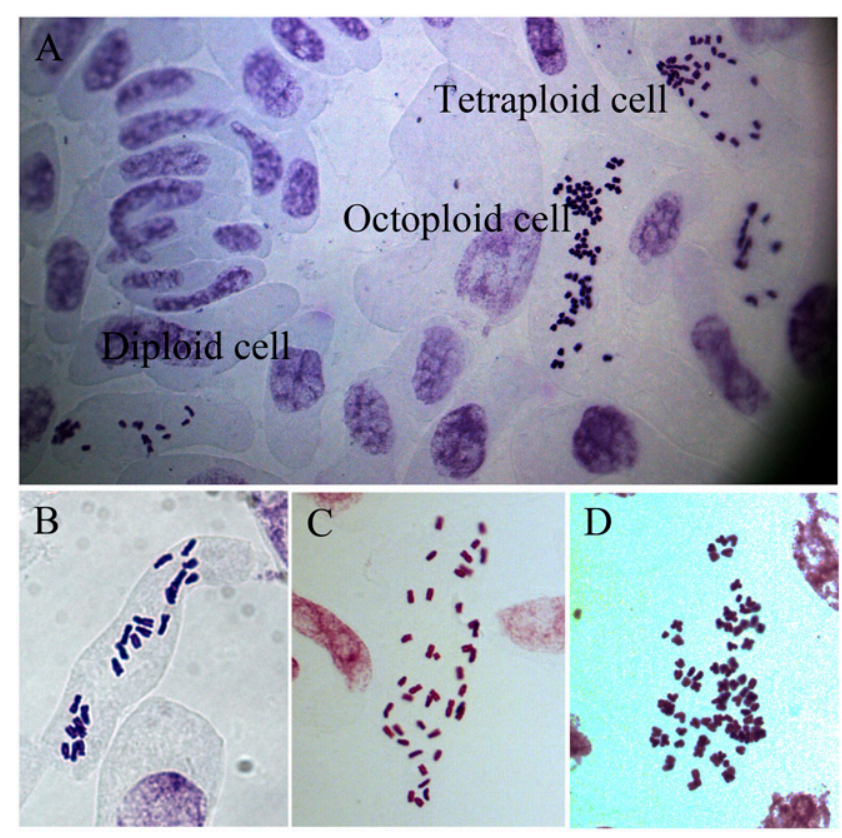

Fig. 1. Root tip chromosomes of the source chimera material plantlet in Echinacea purpurea. (A) Diploid, tetraploid, and octoploid cells in the same microscopic view. (B-D) Chromosomes of diploid cell $(2 x=$ $22)$, tetraploid cell $(4 x=44)$, and octoploid cell $(8 x=88)$. 
Classification of the chimera plantlets. Among all the plantlets propagated above, as diploid cells occurred in only a few plantlets with diploid cell ratios less than $9 \%$, the plantlets with diploid cells were abandoned and only the plantlets with tetraploid and octoploid cells were counted. According to the proportion percentages of tetraploid and octoploid cells, the chimera plantlets propagated above were classified as below:

Grade-1 chimera (chimeras with at least 1.5 -fold more octoploid cells than tetraploid ones);

Grade-2 chimera (chimeras with about equal numbers of octoploid and tetraploid cells); and

Grade-3 chimera (chimeras with at least 1.5 -fold more tetraploid cells than octoploid cells)

\section{Segregation of tetraploid and octoploid plantlets from different chimera type plantlets}

Adventitious shoot formation culture. Leaf, petiole, and root explants were excised from three kinds of chimera types, respectively, and inoculated onto MS medium containing $0.01 \mathrm{mg} \cdot \mathrm{L}^{-1} \mathrm{NAA}$ and different $\mathrm{BA}$ concentrations $\left(0.2,0.4,0.8\right.$, and $\left.1.2 \mathrm{mg} \cdot \mathrm{L}^{-1}\right)$ to induce adventitious shoots (Fig. 2A-C). Each treatment consisted of six bottles and five explants in each bottle. After $45 \mathrm{~d}$, the regenerated shoots were transferred onto MS rooting medium containing $0.1 \mathrm{mg} \cdot \mathrm{L}^{-1} \mathrm{NAA}$. Then their ploidy states were confirmed using the methods described above. The remaining part of the original explants was subcultured to the same and fresh shoot formation medium to induce adventitious shoots for the second passage. The culture periods for adventitious shoot formation and rooting were both $45 \mathrm{~d}$. This was repeated twice (a total of three sequential passages). All the shoots propagated in three sequential passages were examined the ploidy states.

Shoot tip multiplication culture. Shoot tips of Grade-1 and Grade-2 chimeras were inoculated onto the same medium with adventitious shoot formation culture to stimulate the growth of the axillary shoots (Fig. 2D). Each treatment consisted of six bottles and three shoot tips were inoculated in each bottle. After $45 \mathrm{~d}$ culture, the multiplicated axillary shoots were isolated and divided into two groups. A group was inoculated for root induction and later ploidy state confirmation, and the other group was inoculated to the same and fresh shoot multiplication medium for the second passage. The culture periods for multiplication and rooting were both $45 \mathrm{~d}$. This was repeated twice (a total of three sequential passages). All the shoots propagated in three sequential passages were examined the ploidy states.

Medium preparation and culture conditions. All of media contained MS basal medium elements, $3 \%$ sucrose and $0.5 \%$ agar (Company of Jiafeng Horticultural Products, Shanghai, China). The media was adjusted to a $\mathrm{PH}$ of 5.8 and autoclaved at $104 \mathrm{kPa}$ at $121{ }^{\circ} \mathrm{C}$ for $15 \mathrm{~min}$. Each $220-\mathrm{mL}$ bottle contained $35 \mathrm{~mL}$ medium. All the cultures in this study were maintained under lighted conditions with a 12-h photoperiod under cool-white light $\left(\approx 50 \mu \mathrm{mol} \cdot \mathrm{m}^{-2} \cdot \mathrm{s}^{-1}\right)$ in a room with $25-27^{\circ} \mathrm{C}$.
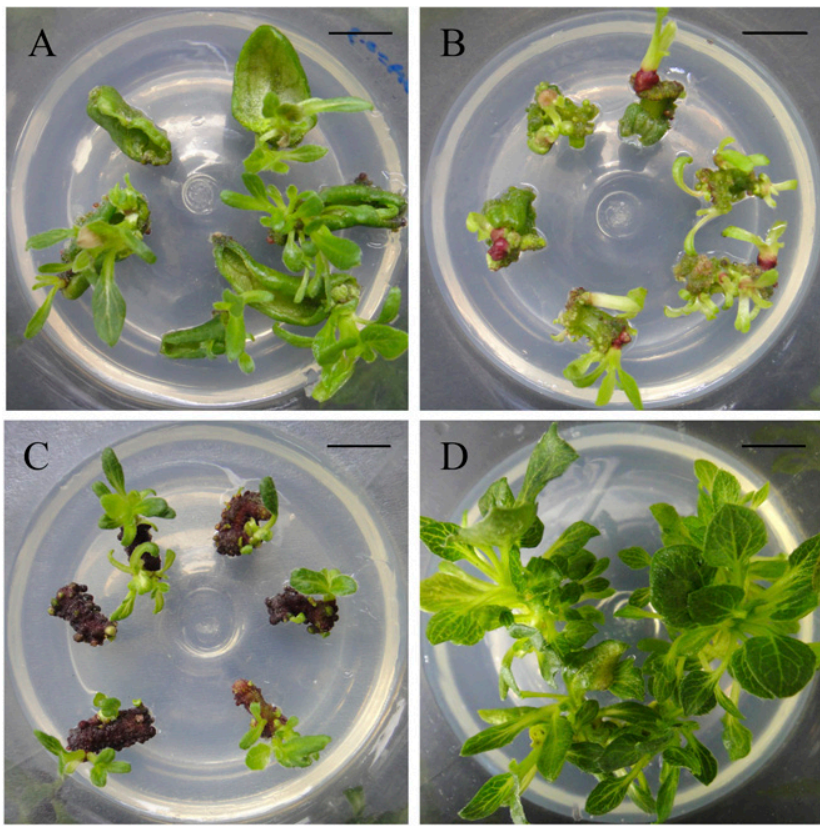

Fig. 2. Adventitious shoot formation and shoot tip multiplication culture of Grade-2 chimera in Echinacea purpurea. (A-C) Leaf, petiole, and root explant in adventitious shoot formation culture. (D) Shoot tip explant in shoot tip multiplication culture. $\mathrm{Bar}=1 \mathrm{~cm}$.
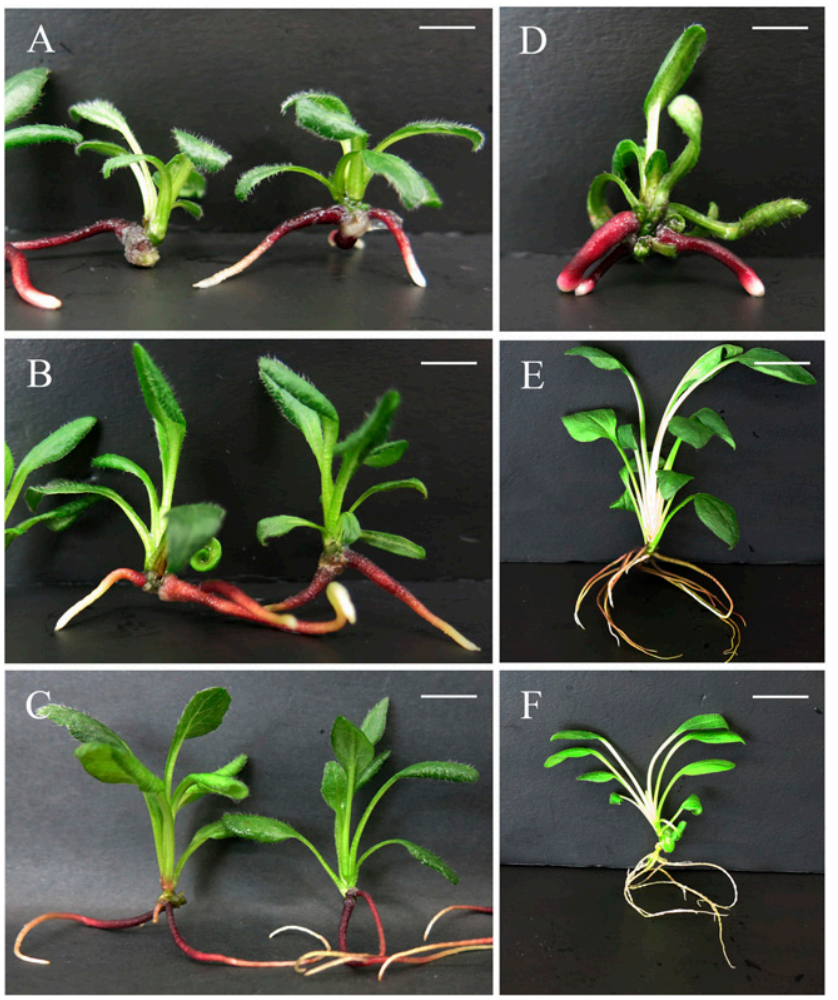

Fig. 3. Morphological comparison of in vitro growing plantlets of various ploidy level states in Echinacea purpurea. (A) Grade-1 chimera, (B) Grade-2 chimera, (C) Grade-3 chimera, (D) octoploid, (E) tetraploid, (F) diploid. $\mathrm{Bar}=1 \mathrm{~cm}$. 
$0.1 \mathrm{~g}$ of the sample powder was extracted with $10 \mathrm{~mL}$ of $70 \%$ ethanol for $30 \mathrm{~min}$ assisted by ultrasonic treatment $(40 \mathrm{kHz})$. The extracted solution was filtered with filter paper. The supernatant was collected and diluted with $70 \%$ ethanol to $10 \mathrm{~mL}$. The solution was filtered again through a $0.45 \mu \mathrm{m}$ microporous membrane, and the filtrate was used as the sample solution for the determination of cichoric acid. Reference standard of cichoric acid was dissolved in appropriate volume of $70 \%$ ethanol and diluted to obtain solutions of $0.02,0.04,0.06,0.08$, and $0.1 \mathrm{mg} \cdot \mathrm{mL}^{-1}$.

The amounts of cichoric acid were analyzed by high-performance liquid chromatography (HPLC). Each sample was conducted in triplicate. Equal amounts $(10 \mu \mathrm{L})$ of each replication were automatically injected into the HPLC system (1260 Infinity; Agilent) equipped with a Inertsil/WondaSil C18 column $(250 \times 4.6 \mathrm{~mm}$, pore size $5 \mu \mathrm{m}$; Shimadzu). The mobile phase was an isocratic 25\% (v/v) acetonitrile:75\% water containing $1.8 \%(\mathrm{v} / \mathrm{v})$ acetic acid at rate of $1 \mathrm{~mL} \cdot \mathrm{min}^{-1}$ for $20 \mathrm{~min}$. The ultraviolet detector G1314F was set at $330 \mathrm{~nm}$. Cichoric acid standard was purchased from Sigma. The cichoric acid concentrations were measured on a dry weight basis $\left(\mathrm{mg} \cdot \mathrm{g}^{-1}\right)$.

Stomata and chloroplast measurement. Length, width, frequency of stomata, and chloroplast number in guard cells were measured in the abaxial side of mature leaves. Stomatal length and width and number of chloroplasts per stomatal guard cell (stained with a drop of distilled water) were measured under magnification of $\times 400$ with Axio Observer A1 microscope (Zeiss). The stomatal density was estimated by the mean number of stomata counted from five different microscopic fields of view at $\times 200$ magnification.

Statistical analysis. All the data were statistically analyzed using SPSS 17.0 software. Significant differences between means were determined using Duncan's multiple range test at $P \leq 0.05$.

\section{Results}

Morphology of different chimera types. The ploidy level noticeably influenced the morphology of the chimeras (Fig. 3). Grade-1 chimera (Fig. 3A) presented more stunted growth, darker green pigmentation, and thicker and rough textured leaves as compared with Grade-2 (Fig. 3B) and Grade-3 chimeras (Fig. 3C). Grade-1 chimera with higher ratio of octoploid cells had thicker roots, hairier leaves, and were closer in shape to pure octoploid plantlets (Fig. 3D). Grade-3 chimera with higher ratio of tetraploid cells had thinner roots, hairless leaves, and were closer in shape to pure tetraploid plantlets (Fig. 3E). The morphology of Grade-2 chimera was between Grade-1 and Grade-3 chimeras.

Segregation of tetraploid and octoploid plantlets from Grade-1, -2, and -3 chimeras in adventitious shoot formation culture. The segregation results are presented in Table 1. Grade-1 chimera segregated a high proportion

Table 1. Effect of chimera types, sequential passage numbers, and 6-benzyladenine (BA) concentrations on the ploidy state of shoots regenerated from petiole explants of Grade-1/-2/-3 chimera in adventitious shoot formation culture in Echinacea purpurea.

\begin{tabular}{|c|c|c|c|c|c|c|}
\hline \multirow[b]{2}{*}{ Chimera type } & \multirow[b]{2}{*}{ Passage no. } & \multirow[b]{2}{*}{$\mathrm{BA}\left(\mathrm{mg} \cdot \mathrm{L}^{-1}\right)$} & \multirow{2}{*}{$\begin{array}{c}\text { No. of plantlets } \\
\text { examined }\end{array}$} & \multicolumn{3}{|c|}{ Ploidy state } \\
\hline & & & & Tetraploid & Octoploid & Chimera \\
\hline \multirow[t]{13}{*}{ Grade-1 } & 1 & 0.2 & 19 & $0(0)$ & $19(100)$ & $0(0)$ \\
\hline & & 0.4 & 9 & $0(0)$ & $7(77.78)$ & $2(22.22)$ \\
\hline & & 0.8 & 12 & $0(0)$ & $8(66.67)$ & $4(33.33)$ \\
\hline & & 1.2 & 6 & $0(0)$ & $5(83.33)$ & $1(16.67)$ \\
\hline & 2 & 0.2 & 11 & $0(0)$ & $10(90.91)$ & $1(9.09)$ \\
\hline & & 0.4 & 26 & $0(0)$ & $13(50.00)$ & $13(50)$ \\
\hline & & 0.8 & 22 & $0(0)$ & $14(63.64)$ & $8(36.36)$ \\
\hline & & 1.2 & 29 & $0(0)$ & $21(72.41)$ & $8(27.59)$ \\
\hline & 3 & 0.2 & 18 & $0(0)$ & $8(44.44)$ & $10(55.56)$ \\
\hline & & 0.4 & 14 & $0(0)$ & $0(0)$ & $14(100)$ \\
\hline & & 0.8 & 17 & $4(23.53)$ & $0(0)$ & $13(76.47)$ \\
\hline & & 1.2 & 29 & $0(0)$ & $7(24.14)$ & $22(75.86)$ \\
\hline & Total & & 212 & $4(1.89)$ & $112(52.83)$ & $96(45.28)$ \\
\hline \multirow[t]{13}{*}{ Grade-2 } & 1 & 0.2 & 53 & $0(0)$ & $0(0)$ & $53(100)$ \\
\hline & & 0.4 & 38 & $0(0)$ & $0(0)$ & $38(100)$ \\
\hline & & 0.8 & 71 & $0(0)$ & $0(0)$ & $71(100)$ \\
\hline & & 1.2 & 70 & $0(0)$ & $0(0)$ & $70(100)$ \\
\hline & 2 & 0.2 & 5 & $0(0)$ & $4(80.00)$ & $1(20)$ \\
\hline & & 0.4 & 21 & $0(0)$ & $2(9.52)$ & $19(90.48)$ \\
\hline & & 0.8 & 17 & $0(0)$ & $3(17.65)$ & $14(82.35)$ \\
\hline & & 1.2 & 54 & $0(0)$ & $1(1.85)$ & $53(98.15)$ \\
\hline & 3 & 0.2 & 6 & $0(0)$ & $0(0)$ & $6(100)$ \\
\hline & & 0.4 & 110 & $0(0)$ & $6(5.45)$ & $104(94.55)$ \\
\hline & & 0.8 & 149 & $17(11.41)$ & $2(1.34)$ & $130(87.25)$ \\
\hline & & 1.2 & 80 & $0(0)$ & $0(0)$ & $80(100)$ \\
\hline & Total & & 674 & $17(2.52)$ & $18(2.67)$ & $639(94.81)$ \\
\hline \multirow[t]{13}{*}{ Grade-3 } & 1 & 0.2 & 19 & $0(0)$ & $0(0)$ & $19(100)$ \\
\hline & & 0.4 & 38 & $7(18.42)$ & $0(0)$ & $31(81.58)$ \\
\hline & & 0.8 & 28 & $6(21.43)$ & $0(0)$ & $22(78.57)$ \\
\hline & & 1.2 & 24 & $16(66.67)$ & $0(0)$ & $8(33.34)$ \\
\hline & 2 & 0.2 & 21 & $16(76.19)$ & $0(0)$ & $5(23.81)$ \\
\hline & & 0.4 & 9 & $5(55.56)$ & $0(0)$ & $4(44.44)$ \\
\hline & & 0.8 & 55 & $33(60)$ & $0(0)$ & $22(40)$ \\
\hline & & 1.2 & 19 & $8(42.11)$ & $0(0)$ & $11(57.89)$ \\
\hline & 3 & 0.2 & 6 & $4(66.67)$ & $0(0)$ & $2(33.33)$ \\
\hline & & 0.4 & 7 & $5(71.43)$ & $0(0)$ & $2(28.57)$ \\
\hline & & 0.8 & 60 & $50(83.33)$ & $0(0)$ & $10(16.67)$ \\
\hline & & 1.2 & 80 & $65(81.25)$ & $0(0)$ & $15(18.75)$ \\
\hline & Total & & 366 & $215(58.74)$ & $0(0)$ & $151(41.26)$ \\
\hline
\end{tabular}

of octoploid plantlets and a little number of chimeras in the first passage. In the second and third passages, proportion of octoploid plantlets decreased and proportion of chimeras increased continuously. A little proportion of tetraploid plantlets was segregated in the third passage. The majority of the recovered plantlets were octoploid plantlets $(52.83 \%)$ and chimeras $(45.28 \%)$ in three sequential passages.

Grade-2 chimera did not segregate tetraploid and octoploid plantlets in the first passage, all the recovered plantlets were chimeras. A few octoploid plantlets were segregated in the second passage and all of the rest were chimeras. In the third passage, proportion of octoploid plantlets decreased and a little proportion of tetraploid plantlets was segregated. The majority of the recovered plantlets were chimeras $(94.81 \%)$ in three sequential passages.

Grade-3 chimera had a high potential to segregate tetraploid plantlets, and the segregation efficiency for tetraploid plantlets increased in successive passages. Octoploid plantlets were not recovered in any passage. The majority of the recovered plantlets were tetraploid plantlets $(58.74 \%)$ in three sequential passages.
The segregation results of leaf (Table 2) and root explants (Table 3) were similar to those of petiole explants (Table 1). The majority of the recovered plantlets from leaf explants of Grade-1 chimera were octoploid plantlets $(42.2 \%)$ and chimeras $(54.99 \%)$; Grade-2 chimera segregated $88.41 \%$ chimeras in three sequential passages (Table 2). The majority of the recovered plantlets from root explants of Grade-1 chimera were octoploid plantlets $(26.24 \%)$ and chimeras $(73.05 \%)$; Grade-2 chimera segregated $87.71 \%$ chimeras in three sequential passages (Table 3). Additionally, the segregation efficiency of tetraploid and octoploid plantlets did not change apparently following BA concentrations either (Tables 1-3). So we deduced that explant types and BA concentrations had no significant effect on the segregation efficiency of tetraploid and octoploid plantlets in adventitious shoot formation culture.

Segregation of tetraploid and octoploid plantlets from Grade-1/-2 chimera in shoot tip multiplication culture. The segregation results are presented in Table 4. Grade-1 chimera segregated a high proportion of chimera plantlets, only a low percentage of octoploid plantlets and no tetraploid plantlets 
Table 2. Effect of chimera types, sequential passage numbers, and 6-benzyladenine (BA) concentrations on the ploidy state of shoots regenerated from leaf explants of Grade-1/-2 chimera in adventitious shoot formation culture in Echinacea purpurea.

\begin{tabular}{|c|c|c|c|c|c|c|}
\hline \multirow[b]{2}{*}{ Chimera type } & \multirow[b]{2}{*}{ Passage no. } & \multirow[b]{2}{*}{$\mathrm{BA}\left(\mathrm{mg} \cdot \mathrm{L}^{-1}\right)$} & \multirow{2}{*}{$\begin{array}{c}\text { No. of plantlets } \\
\text { examined }\end{array}$} & \multicolumn{3}{|c|}{ Ploidy state } \\
\hline & & & & Tetraploid & Octoploid & Chimera \\
\hline \multirow[t]{13}{*}{$\overline{\text { Grade-1 }}$} & 1 & 0.2 & 12 & $0(0)$ & $7(58.33)$ & $5(41.57)$ \\
\hline & & 0.4 & 9 & $0(0)$ & $7(77.78)$ & $2(22.22)$ \\
\hline & & 0.8 & 25 & $0(0)$ & $19(76)$ & $6(24)$ \\
\hline & & 1.2 & 24 & $0(0)$ & $22(91.67)$ & $2(8.33)$ \\
\hline & 2 & 0.2 & 15 & $0(0)$ & $5(33.33)$ & $10(66.67)$ \\
\hline & & 0.4 & 4 & $0(0)$ & $4(100)$ & $0(0)$ \\
\hline & & 0.8 & 47 & $0(0)$ & $32(68.09)$ & 15 (31.91) \\
\hline & & 1.2 & 35 & $0(0)$ & $21(60)$ & $14(40)$ \\
\hline & 3 & 0.2 & 5 & $0(0)$ & $1(20)$ & $4(80)$ \\
\hline & & 0.4 & 5 & $0(0)$ & $2(40)$ & $3(60)$ \\
\hline & & 0.8 & 167 & $11(6.59)$ & $28(16.77)$ & $128(76.64)$ \\
\hline & & 1.2 & 43 & $0(0)$ & $17(39.53)$ & $26(60.47)$ \\
\hline & Total & & 391 & $11(2.81)$ & $165(42.2)$ & 215 (54.99) \\
\hline \multirow[t]{13}{*}{ Grade-2 } & 1 & 0.2 & 10 & $0(0)$ & $1(10)$ & $9(90)$ \\
\hline & & 0.4 & 47 & $0(0)$ & $0(0)$ & 47 (100) \\
\hline & & 0.8 & 58 & $0(0)$ & $0(0)$ & $58(100)$ \\
\hline & & 1.2 & 7 & $0(0)$ & $0(0)$ & $7(100)$ \\
\hline & 2 & 0.2 & $-^{\mathrm{z}}$ & - & - & - \\
\hline & & 0.4 & 41 & $0(0)$ & $9(21.95)$ & $32(78.05)$ \\
\hline & & 0.8 & 32 & $0(0)$ & $4(12.5)$ & $28(77.5)$ \\
\hline & & 1.2 & 4 & $0(0)$ & $0(0)$ & $4(100)$ \\
\hline & 3 & 0.2 & - & - & - & - \\
\hline & & 0.4 & 95 & $11(11.58)$ & $8(8.42)$ & $76(80)$ \\
\hline & & 0.8 & 13 & $1(7.69)$ & $1(7.69)$ & $11(84.62)$ \\
\hline & & 1.2 & 21 & $0(0)$ & $3(14.29)$ & $18(85.71)$ \\
\hline & Total & & 328 & $12(3.66)$ & $26(7.93)$ & $290(88.41)$ \\
\hline
\end{tabular}

${ }^{\mathrm{z}}$ Experiments were not performed as materials were not enough or contamination.

Table 3. Effect of chimera types, sequential passage numbers, and 6-benzyladenine (BA) concentrations on the ploidy state of shoots regenerated from root explants of Grade-1/-2 chimera in adventitious shoot formation culture in Echinacea purpurea.

\begin{tabular}{|c|c|c|c|c|c|c|}
\hline \multirow[b]{2}{*}{ Chimera type } & \multirow[b]{2}{*}{ Passage no. } & \multirow[b]{2}{*}{$\mathrm{BA}\left(\mathrm{mg} \cdot \mathrm{L}^{-1}\right)$} & \multirow{2}{*}{$\begin{array}{c}\text { No. of plantlets } \\
\text { examined }\end{array}$} & \multicolumn{3}{|c|}{ Ploidy state } \\
\hline & & & & Tetraploid & Octoploid & Chimera \\
\hline \multirow[t]{13}{*}{$\overline{\text { Grade-1 }}$} & 1 & 0.2 & 5 & $0(0)$ & $5(100)$ & $0(0)$ \\
\hline & & 0.4 & 4 & $0(0)$ & $2(50)$ & $2(50)$ \\
\hline & & 0.8 & 6 & $0(0)$ & $4(66.67)$ & $2(33.33)$ \\
\hline & & 1.2 & 2 & $0(0)$ & $2(100)$ & $0(0)$ \\
\hline & 2 & 0.2 & $\square^{z}$ & - & - & - \\
\hline & & 0.4 & 4 & $0(0)$ & $2(50)$ & $2(50)$ \\
\hline & & 0.8 & 15 & $0(0)$ & $4(26.67)$ & $11(73.33)$ \\
\hline & & 1.2 & - & - & - & - \\
\hline & 3 & 0.2 & - & - & - & - \\
\hline & & 0.4 & 8 & $1(12.5)$ & $1(12.5)$ & $6(75)$ \\
\hline & & 0.8 & 79 & $0(0)$ & $10(12.66)$ & $69(87.34)$ \\
\hline & & 1.2 & 18 & $0(0)$ & 7 (38.89) & $11(61.11)$ \\
\hline & Total & & 141 & $1(0.71)$ & $37(26.24)$ & $103(73.05)$ \\
\hline \multirow[t]{13}{*}{ Grade-2 } & 1 & 0.2 & 38 & $0(0)$ & $0(0)$ & $38(100)$ \\
\hline & & 0.4 & 19 & $0(0)$ & $0(0)$ & $19(100)$ \\
\hline & & 0.8 & 20 & $0(0)$ & $0(0)$ & $20(100)$ \\
\hline & & 1.2 & 8 & $0(0)$ & $0(0)$ & $8(100)$ \\
\hline & 2 & 0.2 & 25 & $0(0)$ & $2(8)$ & $23(92)$ \\
\hline & & 0.4 & 42 & $0(0)$ & $15(35.71)$ & $27(64.29)$ \\
\hline & & 0.8 & 6 & $0(0)$ & $1(16.67)$ & $5(83.33)$ \\
\hline & & 1.2 & 5 & $0(0)$ & $0(0)$ & $5(100)$ \\
\hline & 3 & 0.2 & 56 & $23(41.07)$ & $0(0)$ & $33(58.93)$ \\
\hline & & 0.4 & 48 & $0(0)$ & $0(0)$ & $48(100)$ \\
\hline & & 0.8 & 96 & $7(7.29)$ & $1(1.04)$ & $88(91.67)$ \\
\hline & & 1.2 & 44 & $0(0)$ & $1(2.27)$ & $43(97.73)$ \\
\hline & Total & & 407 & $30(7.37)$ & $20(4.91)$ & $357(87.71)$ \\
\hline
\end{tabular}

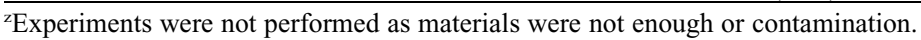

in the first passage. The percentage of chimera plantlets was reduced and a low percentage of tetraploid plantlets was found in the second passage. In the third passage, the percentage of chimera plantlets was further reduced and a higher number of tetraploid plantlets was segregated compared with the second passage. In three sequential passages, increased sharply in the second and third passages. In three sequential passages, the majority of the recovered plantlets were chimera plantlets $(74.75 \%)$ and tetraploid plantlets $(24.24 \%)$.

The results in Table 4 indicated that the occurrence efficiency of tetraploid and octoploid plantlets did not change apparently following BA concentrations either. So BA concentrations had no significant effect on the segregation efficiency of tetraploid and octoploid plantlets in shoot tip multiplication culture.

Morphology and cichoric acid content differences among diploid, tetraploid, and octoploid plants. Stomata size and frequency differed significantly among diploid, tetraploid, and octoploid plants (Fig. 4; Table 5). Stomata length and width in the abaxial side of octoploid (58.01 and $48.52 \mu \mathrm{m})$ leaves were larger than those of tetraploid (49.72 and $41.33 \mu \mathrm{m})$ and diploid (37.26 and 32.23 $\mu \mathrm{m})$ leaves. However, the stomata frequency of octoploid (17.83) was less than that of tetraploid (31.7) and diploid (49.2) leaves. The mean chloroplast number in guard cells of diploid, tetraploid, and octoploid plants was significantly different from each other. The number in octoploid plants (55.33) was more than that in tetraploids (28.43) and diploids (16.68).

The tetraploid and octoploid plants presented obvious delayed growth compared with diploids, especially octoploids (Fig. 4A3, B3, and C3). The original diploid plants had more flower stalks and earlier flowering period than tetraploids. The tetraploids were only in early blooming when the diploids had been in full bloom. However, the tetraploid plants presented stronger growth and darker green pigmentation than diploids. The octoploid plants had dramatically more stunted growth than tetraploids and diploids. They cannot even bloom in the first year.

Results in Table 5 showed significant differences among diploid, tetraploid, and octoploid plants regarding the content of cichoric acid. Cichoric acid content in both the aboveground and underground parts of octoploid plantlets (13.76 and $29.84 \mathrm{mg}^{-1} \mathrm{~g}^{-1}$ ) were higher than that of tetraploid plantlets (10.38 and $22.32 \mathrm{mg} \cdot \mathrm{g}^{-1}$ ), and the content in tetraploids were higher than that in diploid plantlets $\left(8.21\right.$ and $\left.18.42 \mathrm{mg} \cdot \mathrm{g}^{-1}\right)$. The results indicated that induction of polyploidy in $E$. purpurea significantly increased content of cichoric acid.

\section{Discussion}

Segregation of chimeras into pure plants containing only one type of component cells is a long-established topic (Canli, 2003; Canli and Skirvin, 2008; Chua et al., 1981; Hall et al., 1986; Marcotrigiano et al., 1987; McPheeters and Skirvin, 1983, 1989; Ning et al., 2009; Peary et al., 1988; Rosu et al., 1995; Roy et al., 2001). The mechanism was primarily explained using the theory of the tunica-corpus pattern of the meristematic 
Table 4. Effect of chimera types, sequential passage numbers, and 6-benzyladenine (BA) concentrations on the ploidy state of shoots proliferated from shoot tip explants of Grade-1/-2 chimera in shoot tip multiplication culture in Echinacea Purpurea.

\begin{tabular}{|c|c|c|c|c|c|c|}
\hline \multirow[b]{2}{*}{ Chimera type } & \multirow[b]{2}{*}{ Passage no. } & \multirow[b]{2}{*}{$\mathrm{BA}\left(\mathrm{mg} \cdot \mathrm{L}^{-1}\right)$} & \multirow{2}{*}{$\begin{array}{c}\text { No. of plantlets } \\
\text { examined }\end{array}$} & \multicolumn{3}{|c|}{ Ploidy state } \\
\hline & & & & Tetraploid & Octoploid & Chimera \\
\hline \multirow[t]{13}{*}{ Grade-1 } & 1 & 0.2 & 22 & $0(0)$ & $5(22.72)$ & $17(77.78)$ \\
\hline & & 0.4 & 23 & $0(0)$ & $3(13.04)$ & $20(86.96)$ \\
\hline & & 0.8 & 25 & $0(0)$ & $5(20)$ & $20(80)$ \\
\hline & & 1.2 & 16 & $0(0)$ & $4(25)$ & $12(75)$ \\
\hline & 2 & 0.2 & 22 & $4(18.18)$ & $4(18.18)$ & $14(63.64)$ \\
\hline & & 0.4 & 45 & $8(17.78)$ & $10(22.22)$ & $27(60)$ \\
\hline & & 0.8 & 66 & $4(6.06)$ & $24(36.36)$ & $38(57.58)$ \\
\hline & & 1.2 & 76 & $6(7.89)$ & $38(50)$ & $32(42.11)$ \\
\hline & 3 & 0.2 & 21 & $0(0)$ & $6(28.57)$ & $15(71.43)$ \\
\hline & & 0.4 & 38 & $12(31.58)$ & $8(21.05)$ & $18(47.37)$ \\
\hline & & 0.8 & 47 & $9(19.15)$ & $18(38.30)$ & $20(76.6)$ \\
\hline & & 1.2 & 90 & $14(15.56)$ & $40(44.44)$ & $36(40)$ \\
\hline & Total & & 491 & 57 (11.61) & $165(33.6)$ & $269(54.79)$ \\
\hline \multirow[t]{13}{*}{ Grade-2 } & 1 & 0.2 & 70 & $0(0)$ & $3(4.29)$ & $67(95.71)$ \\
\hline & & 0.4 & 36 & $0(0)$ & $0(0)$ & $36(100)$ \\
\hline & & 0.8 & 29 & $0(0)$ & $0(0)$ & $29(100)$ \\
\hline & & 1.2 & 29 & $0(0)$ & $0(0)$ & $29(100)$ \\
\hline & 2 & 0.2 & 35 & $8(22.86)$ & $0(0)$ & $27(77.14)$ \\
\hline & & 0.4 & 35 & $10(28.57)$ & $0(0)$ & $25(71.43)$ \\
\hline & & 0.8 & 32 & $16(50)$ & $2(6.25)$ & $14(43.75)$ \\
\hline & & 1.2 & 23 & $5(21.74)$ & $0(0)$ & $18(78.26)$ \\
\hline & 3 & 0.2 & 77 & $29(37.66)$ & $0(0)$ & $48(62.34)$ \\
\hline & & 0.4 & 50 & $20(40)$ & $0(0)$ & $30(60)$ \\
\hline & & 0.8 & 49 & $19(38.78)$ & $0(0)$ & $30(61.22)$ \\
\hline & & 1.2 & 26 & $12(46.2)$ & $0(0)$ & $14(53.8)$ \\
\hline & Total & & 491 & $119(24.24)$ & $5(1.02)$ & $367(74.75)$ \\
\hline
\end{tabular}
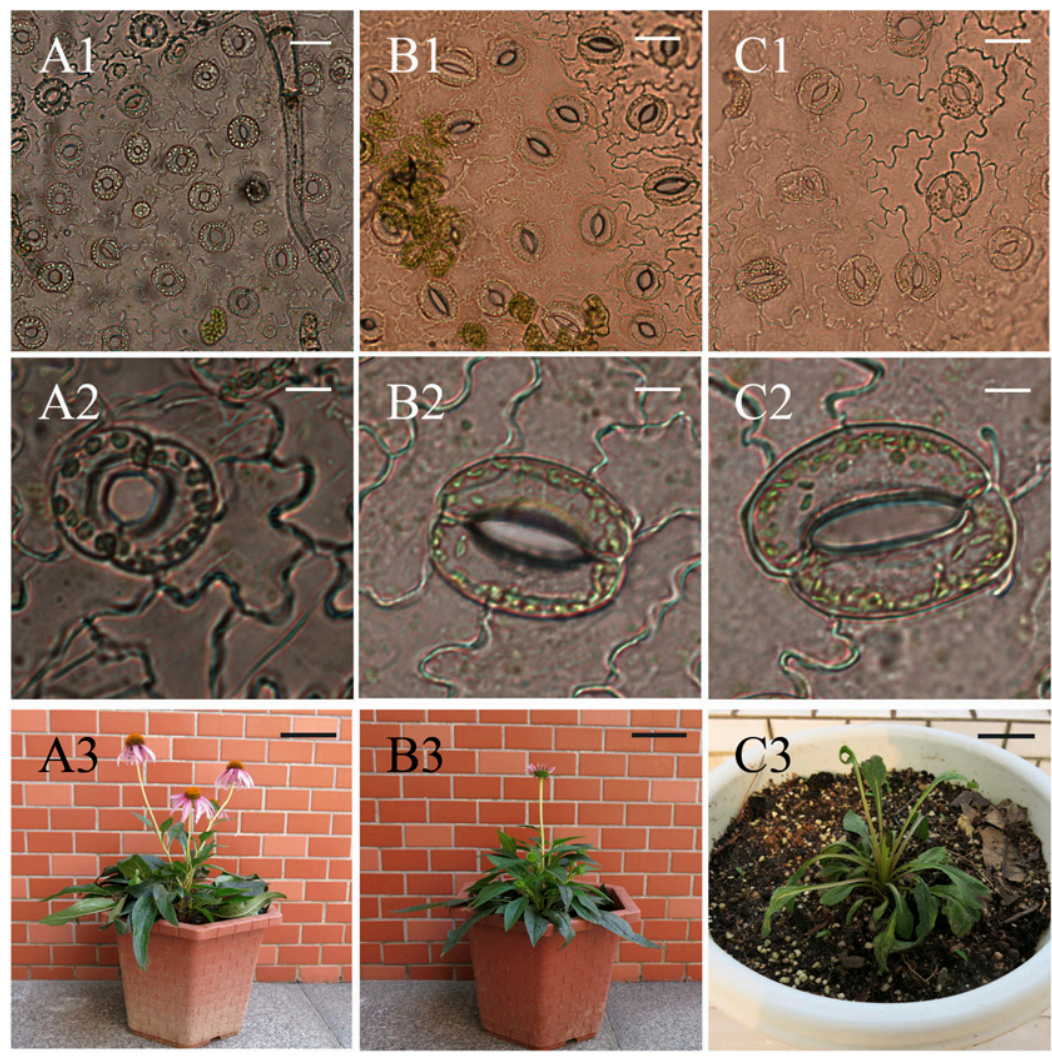

Fig. 4. Comparison of stomata characteristics and morphology differences among diploid, tetraploid, and octoploid plants in Echinacea purpurea. (A1, B1, C1) Stomata size and frequency of diploid, tetraploid, and octoploid plants. Bar $=50 \mu \mathrm{m}$. (A2, B2, C2) Chloroplast number in guard cells of diploid, tetraploid, and octoploid plants. Bar $=10 \mu \mathrm{m}$. (A3, B3, C3) Mature plants of diploid, tetraploid, and octoploid. Bar in A3 and B3 $=10 \mathrm{~cm}$. Bar in $\mathrm{C} 3=2 \mathrm{~cm}$.

region described by Schmidt (1924) and later refined by Tilney-Bassett (1986, 1991). In ploidy chimeras, as the cell mitotic division cycle of the different ploidy level cells were different, the proportion of different ploidy cells were renewed persistently. Thus, the ploidy chimeras were unstable and this was reported in Alocasia (Thao et al., 2003).

In this article, we first classified the chimeras into three types according to the proportion of tetraploid and octoploid cells and described the morphology of three types of chimeras. After segregation culture, various proportions of tetraploid and octoploid plantlets were segregated from three kinds of chimera types. At last, we described the major phenotypic characteristics (including stomata size and frequency, chloroplast numbers in guard cells, and the morphology differences of mature plants) and determined cichoric acid content among diploid, tetraploid, and octoploid lines. This study emphasized several crucial factors that notably influenced the segregation process and provided some evidence regarding the correlation between ploidy level and phenotypic and phytochemical traits.

The results in segregation culture indicated that in vitro segregation of ploidy chimeras was mainly influenced by three factors. 1) The component ratios of different ploidy cells (i.e., the chimera types): pure ploidy plantlets were more easily to be segregated when this ploidy cells hold a comparative high proportion in the chimeric plantlets, e.g., Grade-1 chimera and Grade-3 chimera could segregate high proportions of octoploid and tetraploid plantlets, respectively (Table 1). There was a low segregation efficiency of pure ploidy plantlets when the component ratios of different ploidy cells were similar, e.g., Grade-2 chimera segregated higher percentage of chimeras than pure ploidy plantlets (Tables $1-4$ ). Thus, we concluded that pure ploidy plantlets were easily segregated only when the quantity of this ploidy cells was dominant in the chimeras. 2) The number of sequential passages: Grade-1 chimera segregated a high proportion of octoploid plantlets in the first passage, but the proportion of octoploid plantlets decreased continuously in the second and third passages (Tables 1-4). Grade-2 chimera did not segregate pure ploidy plantlets in the first passage, but obtained tetraploid plantlets with increasing efficiency in the second and third passages (Tables 1-4). 3) The methods of segregation culture: shoot tip multiplication was more effective than adventitious shoot formation when the component ratios of different ploidy cells were similar, e.g., Grade-2 chimera segregated more tetraploid plantlets in shoot tip multiplication than that in adventitious shoot formation culture (Tables 1-4). The differences between the two methods may result from the differences between the explants used (i.e., leaf, petiole, and root explants vs. shoot tip explants), and differences in the two methods themselves. Other factors, e.g., explant types or BA concentrations occasionally influenced the segregation, and just only resulted in some propagation rate (i.e., no. of plantlets examined in Tables 1-4) differences. This was different from previous studies on other chimeras that BA concentration was the main factor influencing the separation of a rose 
Table 5. Comparison of cichoric acid content and stomata characteristics among diploid, tetraploid, and octoploid plants in Echinacea purpurea.

\begin{tabular}{|c|c|c|c|c|c|c|}
\hline \multirow[b]{2}{*}{ Ploidy level } & \multirow[b]{2}{*}{ Stomata frequency } & \multirow[b]{2}{*}{ Stomata length $(\mu \mathrm{m})$} & \multirow[b]{2}{*}{ Stomata width $(\mu \mathrm{m})$} & \multirow[b]{2}{*}{ Chloroplast/guard cells } & \multicolumn{2}{|c|}{ Cichoric acid $\left(\mathrm{mg} \cdot \mathrm{g}^{-1}\right)$} \\
\hline & & & & & Aboveground part & Underground part \\
\hline Diploid & $49.2 \pm 4.53 \mathrm{a}^{z}$ & $37.26 \pm 0.43 \mathrm{c}$ & $32.23 \pm 0.41 \mathrm{c}$ & $16.68 \pm 0.50 \mathrm{c}$ & $8.21 \pm 0.85 b$ & $18.42 \pm 1.73 \mathrm{c}$ \\
\hline Tetraploid & $31.7 \pm 5.56 \mathrm{~b}$ & $49.72 \pm 1.08 \mathrm{~b}$ & $41.33 \pm 0.44 b$ & $28.43 \pm 0.87 \mathrm{~b}$ & $10.38 \pm 0.65 \mathrm{~b}$ & $22.32 \pm 4.27 b$ \\
\hline Octoploid & $17.83 \pm 2.4 \mathrm{c}$ & $58.01 \pm 1.63 \mathrm{a}$ & $48.52 \pm 0.96 \mathrm{a}$ & $55.33 \pm 1.52 \mathrm{a}$ & $13.76 \pm 1.33 \mathrm{a}$ & $29.84 \pm 4.72 \mathrm{a}$ \\
\hline
\end{tabular}

${ }^{2}$ Each value represents the mean \pm SE. Values in each vertical column followed by different letters are significantly different $(P \leq 0.05)$.

chimera (Canli and Skirvin, 2008). It has been reported that higher ploidy level plants need higher BA concentrations than diploid plants in in vitro proliferation (Chen et al., 2012; Nilanthi et al., 2009b). However, BA did not notably influence the occurrence efficiency of octoploid and tetraploid plantlets. Maybe this was the difference between pure ploidies and ploidy chimeras.

The segregation efficiency of pure ploidy plantlets from three kinds of chimeras through two methods and three sequential passage numbers presented some regular change patterns. We deduced that the growth cycle differences of different ploidy level cells were the key factor to these changes. It was assumed that the mitotic cycle of polyploidy lasted longer than diploid. This was reported in Antirrhinum majus (Bennett, 1972) and Hordeum vulgare (Skult, 1969). From interkinesis to division phase, the duration time of polyploidy was longer than diploid. Based on the mitotic duration time differences of different ploidy level plants, the chimeric plants have poor ploidy stability. Furthermore, Stewart et al. (1972) reported that there was quantitative competition between mutational cells and original cells in the chimera. The competition leaded to two results: 1) mutational cells or original cells were substituted by each other and 2) mutational cells and original cells were kept in a dynamic balance. The pure ploidy segregation in this study might be a process of quantitative competition between tetraploid cells and octoploid cells. For instance, in Grade-1 chimera, octoploid cells were dominant in quantity, so a high proportion of octoploid plantlets were segregated in the first passage. As mitotic duration time of tetraploid cells was shorter than that of octoploid cells, the component ratio of tetraploid cells increased and the ratio of octoploid cells decreased, so a lower proportion of octoploid plantlets were segregated in the second passage than that in the first passage. In the third passage, the component ratio of tetraploid cells increased and the ratio of octoploid cells decreased continuously, so the proportion of octoploid plantlets segregated was still lower than that in the second passage, and even a little proportion of tetraploid plantlets was segregated in the third passage. The segregation process of Grade- 2 and Grade- 3 chimeras through two methods and three sequential passages could also be interpreted like this.

The octoploid and tetraploid plants obtained in the segregation culture displayed several morphological differences compared with the original diploid line (Fig. 4; Table 5). These changes were similar to those in some other plant species (Gu et al., 2005; Majdi et al., 2010; Omidbaigi et al., 2010). Many reports found that morphological traits can be effective initial screen to discriminate polyploid plants from diploids, especially stomata characteristics observing, as a simple and efficient method, has been widely used in many plant species, such as Acacia mearnsii (Beck et al., 2003), Aegilops neglecta (Aryavand et al., 2003), Alocasia (Thao et al., 2003), Beta vulgaris (Yudanova et al., 2002), E. purpurea (Abdoli et al., 2013), Lagerstroemia indica (Ye et al., 2010), Morus alba (Chakraborti et al., 1998), P. hybrida (Ning et al., 2009), and Pyrus pyrifolia (Kadota and Niimi, 2002). Octoploid and tetraploid plants presented darker green than diploids. This was probably due to the increased chloroplast number, which is most likely accompanied by enhanced chlorophyll content (Xu et al., 2013). Additionally, polyploidy is also associated with an increase in the number of petals (Kermani et al., 2003), improved resistance to pests, and tolerance to stress (Kehr, 1996; Zhang et al., 2008).

The increasing trend of the cichoric acid content in tetraploid and octoploid plantlets (Table 5) indicated a positive correlation between genomic DNA amount and levels of secondary metabolites. This phenomenon has been previously reported in many other works, e.g., Artemisia annua (Gonzalez and Weathers, 2003; Lin et al., 2011), Cymbopogon (Lavania et al., 2012), Datura stramonium (Berkov and Philipov, 2002), Dracocephalum kotschyi (Zahedi et al., 2014), T. parthenium (Majdi et al., 2010), Thymus persicus (Tavan et al., 2015), and Zinger officinalis (Adaniya and Shira, 2001). Tetraploids were often used to identify differential gene expressions regarding cell growth and functional secondary metabolites (Lin et al., 2011; Zhou et al., 2015). Octoploids had larger organs and more enhanced contents of secondary metabolites than tetraploids, so octoploids could also be attractive for breeding and genetic mechanisms studying as the novel germplasm in other medicinal, ornamental, or agricultural plants.

\section{Literature Cited}

Abdoli, M., A. Moieni, and H.N. Badi. 2013. Morphological, physiological, cytological and phytochemical studies in diploid and colchicine-induced tetraploid plants of Echinacea purpurea (L.). Acta Physiol. Plant. 35:2075-2083.

Adams, K.L. and J.F. Wendel. 2005. Polyploidy and genome evolution in plants. Curr. Opin. Plant Biol. 8:135-141.

Adaniya, S. and D. Shira. 2001. In vitro induction of tetraploid ginger (Zinger officinalis Roscoe) and its pollen fertility and germinability. Sci. Hort. 88:277-287.

Allum, J.F., D.H. Bringloe, and A.V. Roberts. 2007. Chromosome doubling in a Rosa rugosa Thunb. hybrid by exposure of in vitro nodes to oryzalin: The effects of node length, oryzalin concentration and exposure time. Plant Cell Rpt. 26:1977-1984.

Aryavand, A., B. Ehdaie, B. Tran, and J.G. Waines. 2003. Stomata frequency and size differentiate ploidy levels in Aegilops neglecta. Genet. Resources Crop Evol. 50:175-182.

Ault, J.R. 2007. Flower breeding and genetics. p. 801-824. In: N.O. Anserson (ed.). Coneflower: Echinacea species. Springer, Dordrecht, the Netherlands.

Barrett, B. 2003. Medicinal properties of Echinacea: A critical review. Phytomedicine 10:66-86.

Beck, S.L., R.W. Dunlop, and A. Fossey. 2003. Stomatal length and frequency as a measure of ploidy level in black wattle, Acacia mearnsii (de Wild). Bot. J. Linn. Soc. 141:177-181.

Bennett, M.D. 1972. Nuclear DNA content and minimum generation time in herbaceous plants. Proc. R. Soc. Lond. Ser. B, Bio. Sci. 181:109-135.

Berkov, S. and S. Philipov. 2002. Alkaloid production in diploid and autotetraploid plants of Datura stramonium. Pharm. Biol. 40:617-621.

Canli, F.A. 2003. A review on thornless roses. Pak. J. Biol. Sci. 19:1712-1719.

Canli, F.A. and R.M. Skirvin. 2003. Separation of thornless rose chimeras into their (Rosa sp.) consistent genotypes in vitro. Pak. J. Biol. Sci. 19:1644-1648.

Canli, F.A. and R.M. Skirvin. 2008. In vitro separation of a rose chimera. Plant Cell Tiss. Org. 95:353-361.

Chakraborti, S.P., K. Vijayan, B.N. Roy, and S.M.H. Qadri. 1998. In vitro induction of tetraploidy in mulberry (Morus alba L.). Plant Cell Rpt. 17:799-803.

Chen, R., X.L. Chen, Q.L. Li, Y.S. Yang, and H. Wu. 2012. Micropropagation by repeatedly inducing axillary bud formation of different gene dosage purple coneflower plants. Proc. 2012 Intl. Conf. Biomed. Eng. Biotechnol., Macau, 28-30 May 2012

Chen, L.L. and S.L. Gao. 2007. In vitro tetraploid induction and generation of tetraploids from mixoploids in Astragalus membranaceus. Sci. Hort. 112:339-344.

Choffe, K.L., S.J. Murch, and P.K. Saxena. 2000a. Regeneration of Echinacea purpurea: Induction of root organogenesis from hypocotyl and cotyledon explants. Plant Cell Tiss. Org. 62:227-234.

Choffe, K.L., J.M.R. Victor, S.J. Murch, and P.K. Saxena. 2000b. In vitro regeneration of Echinacea purpurea L.: Direct somatic embryogenesis and indirect shoot organogenesis in petiole culture. In Vitro Cell. Dev.-PL. 36:30-36.

Chua, B.U., J.T. Kunisaki, and Y. Sagawa. 1981. In vitro propagation of Dracaena marginata 'Tricolor'. HortScience 16:494.

Dermen, H. 1953. Periclinal cytochimeras and origin of tissues in stem and leaf of peach. Amer. J. Bot. 40:154-168. 
Dermen, H. and F.B. Henry. 1944. A general cytohistological study of colchicine polyploidy in cranberry. Amer. J. Bot. 31:451-463.

Dermen, H. and R.N. Stewart. 1973. Ontogenetic study of floral organs of peach (Prunus persica) utilizing cytochimeral plants. Amer. J. Bot. 60:283-291.

Gonzalez, L.D.J. and P.J. Weathers. 2003. Tetraploid Artemisia annua hairy roots produce more artemisinin than diploids. Plant Cell Rpt. 21:809-811.

Gu, X.F., A.F. Yang, H. Meng, and J.R. Zhang. 2005. In vitro induction of tetraploid plants from diploid Zizyphus jujuba Mill. cv. Zhanhua. Plant Cell Rpt. 24:671-676.

Hall, H.K., H. Quazi, and R.M. Skirvin. 1986. Isolation of a pure thornless loganberry by meristem tip culture. Euphytica 35:10391044.

Harbage, J.F. 2001. Micropropagation of Echinacea angustifolia, E. pallida, and E. purpurea from stem and seed explants. HortScience $36: 360-364$

Harini, K. 2006a. Echinacea purpurea plant named 'Sparkler'. Official gazette of the United States patent and trademark office patents, US PP017298, Terra Nova Nurseries Inc.

Harini, K. 2006b. Echinacea purpurea plant named 'Fancy Frills'. Official gazette of the United States patent and trademark office patents, US PP017209, Terra Nova Nurseries Inc.

Harini, K. 2006c. Echinacea purpurea plant named 'Hope'. Official gazette of the United States patent and trademark office patents, US PP017194, Terra Nova Nurseries Inc.

Harini, K. 2006d. Echinacea purpurea plant named 'Green Eyes'. Official gazette of the United States patent and trademark office patents, US PP017172, Terra Nova Nurseries Inc.

Harini, K. 2008a. Echinacea purpurea plant named 'Raspberry Tart'. Official gazette of the United States patent and trademark office patents, US PP018933, Terra Nova Nurseries Inc.

Harini, K. 2008b. Echinacea purpurea plant named 'Mars'. Official gazette of the United States patent and trademark office patents, US PP018412, Terra Nova Nurseries LLP.

Hartmann, H.T. and D.E. Kester. 1990. Plant propagation principles and practices. p. 484487, 5th ed. Prentice-Hall, Englewood Cliffs, NJ.

Huang, H.P., S.L. Gao, L.L. Chen, and K.H. Wei. 2010. In vitro tetraploid and generation of tetraploids from mixoploids in Dioscorea zingiberensis. Pharmacogn. Mag. 6:51-56.

Hudson, J.B. 2012. Applications of the phytomedicine Echinacea purpurea (purple coneflower) in infectious diseases. J. Biomed. Biotechnol., doi: 10.1155/2012/769896.

Kadota, M. and Y. Niimi. 2002. In vitro induction of tetraploid plants from a diploid Japanese pear cultivar (Pyrus pyrifolia N. cv. Hosui). Plant Cell Rpt. 21:282-286.

Kehr, A.E. 1996. Woody plant polyploidy. Amer. Nurseryman 183:38-47.

Kermani, M.J., V. Sarasan, A.V. Roberts, K. Yokoya, J. Wentworth, and V.K. Sieber. 2003. Oryzalin-induced chromosome doubling in Rosa and its effect on plant morphology and pollen viability. Theor. Appl. Genet. 107:1195-1200.

Koroch, A., H.R. Juliani, J. Kapteyn, and J.E. Simon. 2002. In vitro regeneration of Echinacea purpurea from leaf explants. Plant Cell Tiss. Org. 69:79-83.

Lakshmanan, P., M. Danesh, and A. Taji. 2002. Production of four commercially cultivated Echinacea species by different methods of in vitro regeneration. J. Hort. Sci. Biotechnol. 77:158-163.

Landy, N., G.H. Ghalamkari, M. Toghyani, and F. Moattar. 2011. The effects of Echinacea purpurea L. (purple coneflower) as an antibiotic growth promoter substitution on performance, carcass characteristics and humoral immune response in broiler chickens. J. Med. Plants Res. 5:2332-2338.

Lavania, U.C., S. Srivastava, S. Lavania, S. Basu, N.K. Misra, and Y. Mukai. 2012. Autopolyploidy differentially influences body size in plants, but facilitates enhanced accumulation of secondary metabolites, causing increased cytosine methylation. Plant J. 71:539-549.

Leitch, I.J. and M.D. Bennett. 1997. Polyploidy in angiosperms. Trends Plant Sci. 2:470-476.

Lin, X.Y., Y. Zhou, J.J. Zhang, X. Lu, F.Y. Zhang, Q. Shen, S.Y. Wu, Y.F. Chen, T. Wang, and K.F. Tang. 2011. Enhancement of artemisinin content in tetraploid Artemisia annua plants by modulating the expression of genes in artemisinin biosynthetic pathway. Biotechnol. Appl. Biochem. 58:50-57.

Majdi, M., G. Karimzadeh, M.A. Malboobi, R. Omidbaigi, and G. Mirzaghaderi. 2010. Induction of tetraploidy to feverfew (Tanacetum parthenium Schulz-Bip.): Morphological, physiological, cytological, and phytochemical changes. HortScience 45:16-21.

Manjula, R., J. Praveen, K.V. Subbaiah, G.S.K Swamy, and G. Prabhuling. 2015. Enhancement of in vitro shoot multiplication in banana cv. Rajapuri (AAB) using TDZ. Res. J. Biotechnol. 10:42-47.

Marcotrigiano, M., P.A. Morgan, H.J. Swartz, and J. Ruth. 1987. Histogenic instability in tissue culture-proliferated strawberry plants. J. Amer. Soc. Hort. Sci. 112:583-587.

Mazri, M.A. 2015. Role of cytokinins and physical state of the culture medium to improve in vitro shoot multiplication, rooting and acclimatization of date palm (Phoenix dactylifera L.) cv. Boufeggous. J. Plant Biochem. Biotechnol. 24:268-275.

McGregor, R.L. 1968. The taxonomy of the genus Echinacea (Compositae). University of Kansas, Sci. Bul. 48:113-142.

McPheeters, K.D. and R.M. Skirvin. 1983. Histogenic layer manipulation in chimeral 'Thornless Evergreen' trailing blackberry. Euphytica 32:351-360.

McPheeters, K.D. and R.M. Skirvin. 1989. Somaclonal variation among ex vitro 'Thornless Evergreen' trailing blackberries. Euphytica 42:155-162.

Mechanda, S.M., B.R. Baum, D.A. Johnson, and J.T. Arnason. 2003. Direct shoot regeneration from leaf segments of mature plants of Echinacea purprea (L.) Moench. In Vitro Cell. Dev.-PL. 39:505-509.

Murashige, T. and F. Skoog. 1962. A revised medium for rapid growth and bioassays with tobacco tissue cultures. Physiol. Plant. 15:473497.

Nagar, D.S., S.K. Jha, and J. Jani. 2015. Direct adventitious shoot bud formation on hypocotyls explants in Millettia pinnata (L.) Panigrahi: A biodiesel producing medicinal tree species. Physiol. Mol. Biol. Plants 21:287-292.

Neilson-Jones, W. 1969. Plant chimeras. 2nd ed. Methuen and Co. Ltd., London.

Nilanthi, D., X.L. Chen, F.C. Zhao, Y.S. Yang, and $\mathrm{H}$. Wu. 2009a. Induction of tetraploids from petiole explants through colchicine treatments in Echinacea purpurea L. J. Biomed. Biotechnol., doi: 10.1155/2009/343485.
Nilanthi, D., X.L. Chen, F.C. Zhao, Y.S. Yang, and H. Wu. 2009b. Influence of gene dose on in vitro culture responses of purple coneflower (Echinacea purpurea L.). Proc. 3rd. Intl. Conf. Bioinfo. Biomed. Eng., Beijing, China, 11-16 June 2009.

Ning, G.G., X.P. Shi, H.R. Hu, Y. Yan, and M.Z. Bao. 2009. Development of a range of polyploid lines in Petunia hybrida and the relationship of ploidy with the single-/double-flower trait. HortScience 44:250-255.

Omidbaigi, R., M. Mirzaeea, M.E. Hassani, and M. Sedghi-Moghadam. 2010. Induction and identification of polyploidy in basil (Ocimum basilicum L.) medicinal plant by colchicine treatment. Intl. J. Plant Prod. 4:87-98.

Otto, S.P. and J. Whitton. 2000. Polyploidy incidence and evolution. Annu. Rev. Genet. 34:401-437.

Pan, Z.G., C.Z. Liu, S.M.A. Zobayed, and P.K. Saxena. 2004. Plant regeneration from mesophyll protoplasts of Echinacea purpurea. Plant Cell Tiss. Org. 77:251-255.

Peary, J.S., R.D. Lineberger, T.J. Malinich, and M.K. Wertz. 1988. Stability of leaf variegation in Saintpaulia ionantha during in vitro propagation and during chimeral separation of a pinwheel flowering form. Amer. J. Bot. 75:603-608.

Petersen, K.K., P. Hagberg, and K. Kristiansenl. 2003. Colchicine and oryzalin mediated chromosome doubling in different genotypes of Miscanthus sinensis. Plant Cell Tiss. Org. 73:137-146.

Pryor, R.L. and L.C. Frazier. 1968. Colchicine induced tetraploid azaleas. HortScience 3:283-286.

Pugh, N.D., H. Tamta, P. Balachandran, X. Wu, J. Howell, F.E. Dayan, and D.S. Pasco. 2008. The majority of in vitro macrophage activation exhibited by extracts of some immune enhancing botanicals is due to bacterial lipoproteins and polysaccharides. Intl. J. Immunopharmacol. 8:1023-1032.

Ramanna, M.S. and E. Jacobsen. 2003. Relevance of sexual polyploidization for crop improvement: A review. Euphytica 133:3-18.

Rosu, A., R.M. Skirvin, A. Bein, M.A. Norton, and M. Kushad. 1995. The development of putative adventitious shoots from a chimera thornless rose (Rosa multiflora Thunb. ex J. Murr.) in vitro. J. Hort. Sci. 70:901-907.

Roy, A.T., G. Leggett, and A. Koutoulis. 2001. In vitro tetraploid induction and generation of tetraploids from mixoploids in hop (Humulus lupulus L.). Plant Cell Rpt. 20:489-495.

Satina, S. and A.F. Blakeslee. 1941. Periclinal chimeras in Datura stramonium in relation to development of leaf and flower. Amer. J. Bot. 28:862-871.

Satina, S., A.F. Blakeslee, and A.G. Avery. 1940. Demonstration of the three germ layers in the shoot apex of Datura by means of induced polyploidy in periclinal chimeras. Amer. J. Bot. 27:895-905.

Schmidt, A. 1924. Histologische studien an phanerogamen vegetationspunkten. Bot. Arch. 8:345-404.

Shao, J.Z., C.L. Chen, and X.X. Deng. 2003. In vitro induction of tetraploid in pomegranate (Punica granatum). Plant Cell Tiss. Org. 75:241-246.

Skult, H. 1969. Growth and cell population kinetics of tritiated thymidine labelled roots of diploid and autotetraploid barley. Acta Acad. Aboensis. Ser. B. 29:1-15.

Stewart, R.N., F.G. Meyer, and H. Dermen. 1972. Camella + 'Daisy Eagleson', a graft chimera of 
Camellia sasanqua and C. Japonica. Amer. J. Bot. 59:515-524.

Tavan, M., M.H. Mirjalili, and G. Karimzadeh. 2015. In vitro polyploidy induction: Changes in morphological, anatomical and phytochemical characteristics of Thymus persicus (Lamiaceae). Plant Cell Tiss. Org. 22:573-583.

Thao, N.T.P., K. Ureshino, I. Miyajima, Y. Ozaki, and H. Okubo. 2003. Induction of tetraploids in ornamental Alocasia through colchicine and oryzalin treatments. Plant Cell Tiss. Org. 72:19-25.

Tilney-Bassett, R.A.E. 1986. Plant chimeras. Edward Arnold, Baltimore, MD.

Tilney-Bassett, R.A.E. 1991. Plant chimeras. Camb. Univ. Press, London.

Wan, Y., J.F. Petolin, and J.M. Widholm. 1989. Efficient production of doubled haploid plants through colchicine treatment of anther-derived maize callus. Theor. Appl. Genet. 77:889-892.

Xu, C.G., T.X. Tang, R. Chen, C.H. Liang, X.Y. Liu, C.L. Wu, Y.S. Yang, D.P. Yang, and H. Wu.
2013. A comparative study of bioactive secondary metabolite production in diploid and tetraploid Echinacea Purpurea (L.) Moench. Plant Cell Tiss. Org., doi:10.1007/s11240-0130406-Z.

Ye, Y.M., J. Tong, X.P. Shi, W. Yuan, and G.R. Li. 2010. Morphological and cytological studies of diploid and colchicine-induced tetraploid lines of crape myrtle (Lagerstroemia indica L.). Sci. Hort. 124:95-101.

Yudanova, S.S., E.I. Maletskaya, and S.I. Maletskii. 2002. Variability of chloroplast number in populations of stomatal guard cells in sugar beet Beta vulgaris L. Russ. J. Genet. 38:72-78.

Zahedi, A.A., B. Hosseini, M. Fattahi, E. Dehghan, H. Parastar, and H. Madani. 2014. Overproduction of valuable methoxylated flavones in induced tetraploid plants of Dracocephalum kotschyi Boiss. Bot. Stu. 55:22.

Zhang, Z., H. Dai, M. Xiao, and X. Liu. 2008. In vitro induction of tetraploids in Phlox subulata L. Euphytica 159:59-65.
Zhang, X.Y., C.G. Hu, and J.L. Yao. 2010. Tetraploidization of diploid Dioscorea results in activation of the antioxidant defense system and increased heat tolerance. J. Plant Physiol. 167:88-94

Zhou, Y.Y., L. Kang, S.Y. Liao, Q. Pan, X.H. Ge, and Z.Y. Li. 2015. Transcriptomic analysis reveals differential gene expressions for cell growth and functional secondary metabolites in induced autotetraploid of Chinese woad (Isatis indigotica Fort.). PLoS One, doi:10.1371/journal. pone. 0116392.

Zobayed, S.M.A. and P.K. Saxena. 2003. In vitro regeneration of Echinacea purpurea L.: Enhancement of somatic embryogenesis by indolebutyric acid and dark pre-incubation. In Vitro Cell. Dev-PL. 39:605-612.

Zonneveld, B.J.M. 2007. Nuclear DNA content of ploidy chimeras of Hosta Tratt. (Hostaceae) demonstrate three apical layers in all organs, but not in the adventitious root. Plant Syst. Evol. 269:29-38. 